\title{
Evaluation of Cissus populnea gum as a directly compressible matrix system for tramadol hydrochloride extended-release tablet
}

\author{
Olutayo Ademola Adeleye ${ }^{1 *}$, Mbang N. Femi-Oyewo ${ }^{1}$, Michael A. Odeniyi ${ }^{2}$, Tolulope O. Ajala ${ }^{2}$ \\ ${ }^{1}$ Department of Pharmaceutics and Pharmaceutical Technology, Olabisi Onabanjo University, Ago Iwoye, Nigeria. \\ ${ }^{2}$ Department of Pharmaceutics and Industrial Pharmacy, University of Ibadan, Ibadan, Oyo State, Nigeria
}

\section{ARTICLE INFO \\ Received on: 21/12/2018 \\ Accepted on: 31/01/2019 \\ Available online: 28/02/2019}

\section{Key words:}

Tramadol hydrochloride tablet, cissus gum, xanthan gum, direct compression, compaction.

\begin{abstract}
The aim of this study was to evaluate and compare the compactibility, mechanical and release properties of tramadol tablets prepared by direct compression using cissus gum, a naturally occurring plant polymer as directly compressible excipient in comparison with xanthan gum. Compactibility was measured by Heckle, mechanical properties by tensile strength and friability, and release properties by dissolution profile. Student $t$-test with GraphPad Prism 5 was used to identify differences between data at $p<0.05$. The result showed that the Py of xanthan formulation was significantly lower than cissus formulations $(p=0.03)$. Onset of plastic deformation was directly dependent on the concentration of the polymer and the properties of the active ingredient. The presence of the active ingredient retarded the onset of plastic deformation. There was increase in crushing strength and tensile strength with decrease in friability as the concentration of the polymer increased in all formulations. The mechanical properties of cissus gum and xanthan gum formulations were not significantly different $(p>0.05)$. Tramadol dissolution decreased as the concentration of the polymers increased. Cissus gum has some properties that would make it suitable as direct compressible excipient in matrix systems for extended-release.
\end{abstract}

\section{INTRODUCTION}

Pharmaceutical excipients are usually derived from natural (animal, vegetable, and mineral) and synthetic origin (Giorgio and Patrizia, 2003). The additives developed from natural sources are still the best for the production of pharmaceuticals. This is because of their reduced toxicity, low cost, local availability, soothing action, non-irritant nature, relative abundance, biocompatibility, improved patient tolerance, and public acceptance compared to synthetic excipients (Anroop et al., 2005; Bharadia et al., 2004; Kaushik et al., 2016; Kulkarni et al., 2002; Pawar and D'mello, 2004; Varshosaz et al., 2006). Direct compression is a method of tablet production among other methods such as wet granulation and dry granulation; it simply

"Corresponding Author

Olutayo Ademola Adeleye, Department of Pharmaceutics and

Pharmaceutical Technology, Olabisi Onabanjo University, Ago Iwoye,

Nigeria.E-mail: olutayoadeleye@yahoo.com involves the direct compression of the blend of powdered materials into tablets without modification of the physical characteristic of the materials. This method is becoming very popular because of it being economical, cheap, and an efficient technological process. Direct compression involves few unit operation processes and manufacturing steps, reduced processing time and costs, and less number of equipment (Hindiyeh et al., 2018; Singh et al., 2014). Hydrophilic polymers are popular and suitable for delaying drug release, and interest continues in the use of polymers in controlled drug delivery systems (Gade and Murthy 2011; Genc et al., 1999; Jan et al., 2012; Khan and Jiabi 1998; Manjula et al., 2014; Muhammad et al., 2014; Reddy and Archana 2018).

Hydrophilic polymers in matrix systems do not disintegrate; in the presence of an aqueous medium, hydration develops immediately with the production of a highly viscous gelatinous boundary, which serves as a barrier that controls the release of drug from the matrix system (Talukder et al., 1996). These systems are called swellable controlled release systems. The hydrophilic polymeric matrix system is made up of the hydrophilic polymer, the drug, and other adjuvants, which are 
evenly distributed within the matrix. These systems generally depended on wetting and hydration of the polymer, and dissolution to achieve modulated drug release (Williams et al., 2002).

Tramadol hydrochloride is a centrally acting opioid analgesic. It is used in the management of pains. The peak concentration of sustained release tramadol preparation is reached after 4.9 hours with an oral bioavailability of $87 \%-95 \%$. It has an elimination half-life of 6 hours (Grond and Sablotzki, 2004) and thus requires dosing every 6 hours in order to maintain optimal blood concentration for the relief of pain as reported by Raber et al. (1999).

Cissus gum obtained from Cissus populnea (Guill and Per), a climbing plant, has been explored in other studies as a binder, controlled release agent, suspending agent, and emulsifying agent (Abioye et al., 2000; 2001; Adeleye et al., 2011; Eichie and Amalime 2007; Emeje et al., 2009; Ibrahim et al., 2002). In order to expand the usefulness of cissus gum, an attempt was made to evaluate its properties in direct compression. The aim of the present study, therefore, was to evaluate the compactibility, mechanical, and release properties of tramadol hydrochloride tablets prepared by direct compression using cissus gum, as a directly compressible excipient. This was done in comparison with xanthan gum, a naturally sourced standard adhesive as a directly compressible excipient.

\section{MATERIALS AND METHODS}

\section{Materials}

Tramadol hydrochloride used in the study was a gift from Uripharm Specialties Ltd (Lagos, Nigeria). Cissus gum was extracted in the Laboratory of the Department of Pharmaceutics and Industrial Pharmacy, University of Ibadan, Ibadan, Nigeria. Xanthan gum was obtained from Jungbenzlauer Ges.M.B.H. Handelsgericht Wien, Germany. Lactose was also obtained from DMV Veghel, Netherlands. Other solvents and chemicals were of analytical grade.

\section{Methods}

\section{Preparation of Cissus gum}

The gum was obtained from the stem of Cissus populnea according to the method adapted by Adeleye et al. (2015a). The sliced stem was macerated in distilled water for 24 hours, followed by filtration of the viscous solution with a muslin bag. The viscous solution was then treated with acetone to precipitate the gum. The precipitate was dried at $50^{\circ} \mathrm{C}$ for 24 hours in an oven and pulverized using a laboratory blender (Model 857 Williamette Industries, Bowing Green Kentucky USA).

\section{Preparation of powder blend}

The formulations in Table 1 were prepared by mixing tramadol hydrochloride, the polymer-Cissus gum or Xanthan gum - and lactose (where required) uniformly. The mixing was done in a tumbling mixer for 10 minutes to form a homogenous blend.

\section{Bulk, tapped, and relative density measurements}

The bulk and tapped densities of each of the formulations were determined by pouring $25.0 \mathrm{~g}$ of each of the formulations gradually into a $100 \mathrm{ml}$ graduated glass measuring cylinder with a diameter of $12.6 \mathrm{~mm}$ through a funnel at an angle of $45^{\circ}$. The height reached by the powder was measured and the volume and density were calculated appropriately (Mohammadi and Harnby, 1997).

The bulk density (loose), $P$ was calculated using Eq. (1):

$$
P=m / v
$$

Where, $m$, in grams, is the weight of formulation in the cylinder and $v$, in $\mathrm{cm}^{3}$, is the volume occupied by the formulation. Determinations were done in triplicate.

Tapped density was determined by tapping $25 \mathrm{~g}$ of formulation in the graduated measuring cylinder manually on a wooden surface at height of 7 inches. One hundred taps were applied at a standard rate of 38 taps per minute (Reus-Medina et al., 2004).

Relative density $D_{o}$ of each formulation was obtained from the ratio of the loose density to its particle density (Heckel, 1961).

\section{Particle density measurement}

The particle density of each formulation was determined by the pycnometer method using liquid immersion technique with xylene as the displacement liquid (Odeniyi et al., 2011). The pycnometer bottle $(50 \mathrm{ml})$ was weighed empty with the stopper $(W)$. It was filled with xylene to the brim and excess was wiped off with an absorbent paper, and the weight with the stopper was noted as $\left(W_{1}\right)$. The difference between $W$ and $W_{1}$ was recorded as $W_{2}$. Two gram of each formulation was weighed $\left(W_{3}\right)$ and transferred into the pycnometer bottle and filled with xylene to the brim. The excess solvent was wiped off and the bottle weighed again with the stopper $\left(W_{4}\right)$. The particle density, $\mathrm{Pt}\left(\mathrm{g} / \mathrm{cm}^{3}\right)$, was calculated using Eq. (2):

$$
\mathrm{Pt}=W_{2} \cdot W_{3} / 50\left(W_{3}-W_{4}+W+W_{2}\right)
$$

Table 1. Tramadol hydrochloride matrix tablet formulations.

\begin{tabular}{ccccc}
\hline Formulation code & Tramadol $\%{ }^{\mathrm{w} / \mathrm{w}}$ & Xanthan gum $\% \mathrm{w} /{ }_{\mathrm{w}}$ & Cissus gum $\% \mathrm{w}_{\mathrm{w}}$ & Lactose $\% \mathrm{w}_{\mathrm{w}}$ \\
\hline FC & - & - & 75 & 25 \\
$\mathrm{FC} 1$ & 25 & - & 25 & 50 \\
$\mathrm{FC} 2$ & 25 & - & 50 & 25 \\
$\mathrm{FC} 3$ & 25 & - & 75 & - \\
FX & - & 75 & - & 25 \\
FX1 & 25 & 25 & - & 50 \\
FX2 & 25 & 50 & - & 25 \\
FX3 & 25 & 75 & - & - \\
\hline
\end{tabular}




\section{Angle of repose}

This was determined by allowing a specific mass of material to flow freely through a funnel from a particular height to form a conical heap on a white paper placed on a horizontal surface. The diameter of the cone was measured and the angle of repose was determined by Eq. (3) (Potu et al., 2011).

$$
\tan \Theta=h / r
$$

Where $\Theta$ is the angle of repose (the angle made by the heap with the base), $h$ is the height of the heap of powder, and $r$ is the radius of the cone. Determinations were made in triplicate.

\section{Hausner's ratio and Carr's index}

The Hausner's ratio and Carr's compressibility index were calculated using Eqs. (4) and (5), respectively (Carr, 1965; Hausner, 1967).

$$
\begin{aligned}
\text { Hausner ratio }= & \text { Tapped density/ Bulk density } \\
\text { Carr's Index }= & \text { Tapped density }- \text { Bulk density/Tapped } \\
& \text { density } 100
\end{aligned}
$$

\section{Tablet compression}

The formulations containing the powder mixture were compressed for 30 seconds into $400 \mathrm{mg}$ tablet compacts at six different compression loads using a hydraulic hand press (Model C, Carver Jnc., Menomonee Falls, $W_{1}$ ) with a $10.5 \mathrm{~mm}$ die and flat-faced punches lubricated with a $2 \%$ dispersion of magnesium stearate in acetone before each compression. The tablets were ejected and stored in airtight containers over silica gel for 24 hours to allow for elastic recovery and hardening.

Tablets compressed with a compression load of 113.16 $\mathrm{M} \mathrm{Nm}^{-2}$ were selected for the evaluation of mechanical and release properties of the tablets.

\section{Tablet tensile strength}

The force $(N)$ required to break each tablet was determined by the procedure of Fell and Newton (1970) using a tablet hardness tester (DKB instrument, Mumbai. Model EH 01). Tablets were placed between the spindle and the anvil of the hardness tester, and the pressure was applied until the tablet split diametrically. Determinations were made in triplicate for each batch of the tablet tested.

The tensile strength, $T$, in $\mathrm{N} \mathrm{mm}^{-2}$, of the tablets was calculated from Eq. (6) (Fell and Newton, 1970; Hiestand et al., 1977):

$$
T=2 \cdot F / \pi \cdot d \cdot t
$$

Where $F$ is the force required to cause breakage, $\pi$ is $3.14, d$ is the tablet diameter, and $t$ is the tablet thickness.

\section{Tablet friability}

The percentage friability of the tablet was determined using the Veego tablet friability apparatus (Veego Scientific Devices, Mumbai, India). The weights of 10 tablets were taken collectively and the tablets were placed in the friabilator, which was then operated for 4 minutes at $25 \mathrm{rpm}$. The tablets were collected, dusted, and weighed again (Adeleye et al., 2015b). The percentage weight loss was calculated as the percent friability. Determinations were made in triplicate.

\section{Tablet dissolution test}

The release rate of tramadol hydrochloride from the tablets was examined by rotating basket USP Dissolution Apparatus (Model NE4-COPD, Copley scientific, Nottingham, UK) operated at $50 \mathrm{rpm}$ with $900 \mathrm{ml}$ of $0.1 \mathrm{~mol} . \mathrm{l}^{-1}$ hydrochloric acid at $37.0^{\circ} \mathrm{C} \pm 0.5^{\circ} \mathrm{C}$ as the dissolution medium. Five milliliter samples were withdrawn and immediately replaced with $5 \mathrm{ml}$ of fresh 0.1 mol. $1^{-1}$ hydrochloric acid at 1-hour interval for 12 hours maintained at the same temperature. The amount of tramadol released was analyzed using a spectrophotometer (Jenway UV780 print UV-Spec) at a wavelength of $271 \mathrm{~nm}$.

\section{Statistical analysis}

Statistical analysis was performed with GraphPad Prism 5. Some data were presented as mean \pm standard deviation $(\bar{X} \pm$ $\mathrm{SD})$. Student's $t$-test was used to identify differences between the parameters evaluated. Differences were considered to be statistically significant at a $p$ value of $<0.05$.

\section{RESULTS AND DISCUSSION}

\section{Precompression studies}

\section{Density measurements}

The values of loose bulk density, tapped density, particle density, and the relative density at zero pressure $\left(D_{o}\right)$ for the formulations are as shown in Table 2.

The loose bulk, tapped, and relative densities of the formulations containing the active ingredient (FC1 to FC3 and FX1 to FX3) increased with an increase in polymer concentration. Formulations containing Cissus gum had lower values of loose bulk, tapped, and relative densities than Xanthan gum. The placebo formulation containing cissus gum or xanthan gum had higher values of loose bulk, tapped, and relative densities than each of the corresponding formulation containing the active ingredient.

The results of particle density as presented in Table 2 indicated that formulations containing cissus had higher particle density than those of formulations containing xanthan, which was significantly different $(p=0.002)$. This is probably due to the fact that cissus formulations are harder than xanthan formulations. As reported by Itiola and Pilpel (1991) dense, hard granules may require higher compressive forces to produce a cohesive compact. It is thus expected that at any given pressure, powders with smaller particle density (Xanthan gum) should yield more cohesive compact than those with bigger particle density (Cissus gum).

\section{Flow properties}

The angle of repose is a qualitative assessment of the internal cohesiveness and frictional effects under low external loading as may apply in powder mixing or filling operations in tablet die or capsule shell (Marshall, 1986). Percentage compressibility (Carr's index) is a qualitative descriptive assessment of the compressibility and flowability of powder while Hausner ratio is indicative of interparticle friction. As the values of these three parameters increase, the flow of powder is expected to decrease. When the angle of repose is more than $50^{\circ}$ flow is poor, while below $30^{\circ}$ indicates good flow and above $40^{\circ}$ is suggestive of irregular flow. Carr's index values of 5\%-15\% indicate excellent flow, 
$16 \%-18 \%$ indicates a good flow, and $19 \%-25 \%$ suggests fair flow, while $26 \%-35 \%$ suggests poor flow. In addition, Carr's index value above $40 \%$ is indicative of cohesive powder and very poor flow characteristic (Carr, 1965). Hausner ratio values of less than 1.25 indicate good flow, while values greater than 1.25 indicate poor flow (Staniforth, 2002).

The values of Hausner's ratio, Carr's index, and angle of repose of the formulations as presented in Table 3 indicated that all the formulations including placebos have Hausner's ratio above 1.25 , which is an indication that the ingredients of the formulation have poor flow. However, Carr's index of all formulations was between $19.17 \%$ and $27.50 \%$ indicating a good to fair flow of the entire powder blend. Formulations containing xanthan have good flow, while formulations containing cissus has fair flow properties according to the results obtained for Carr's index determinations. The result of the angle of repose as indicated in Table 3 shows that all formulations containing xanthan gum have values above $30^{\circ}$ but below $40^{\circ}$ indicating irregular flow, while formulations containing cissus have values above $40^{\circ}$ indicating poor flow. The values of the angle of repose, Carr's index, and Hausner's ratio were not consistent. This may probably be due to the fact that powder flow is complex and multidimensional depending on many powder characteristics and other factors (Prescot and Barnum, 2000). In this study, powder blend of all formulation was manually fed into the die of a hand press manual compression machine; thus, flow properties were not of essence since it is only experimental. It will only become important on a rotary press where large production is required. In this case, the flow will have to be improved by the incorporation of a glidant to produce tablets of uniform weight.

\section{Compaction studies of the formulations}

Particle deformation was evaluated by measuring volume reduction (changes in relative density of tablets) of the powder blend in the die subjected to varying compression pressures. The Heckel equation was applied to study the compaction of the formulations as shown in Figures 1 and 2.

The parameters obtained from the Heckel plots are presented in Table 4. The yield pressure, $P_{y}$ is the reciprocal of the slope, and it is inversely associated to the ability of a material to deform plastically under pressure; $A$ is the intercept, from which $D_{A}$ values were obtained. The difference between $D_{A}$ and $D_{o}$ is $D_{B}$, which is the relative density of the phase of particle rearrangement during the initial stages of compression.

The relative density, $D_{o}$, is the ratio of loose density to the particle density of the powder blend. It is the first phase of densification from the fall of powder from the hopper due to gravitational force into the die. Formulations containing xanthan had a significantly higher value of $D_{o}$ compared with cissus $(p=0.01)$. This implies that xanthan had a higher degree of initial packing in the die from the fall of powder from the hopper.

The relative density, $D_{B}$, is the re-arrangement phase of particles in the die during the initial stages of compression under low applied pressure before the commencement of deformation. Formulations containing cissus had a significantly higher value of $D_{B}$ compared with xanthan.

This is expected since formulations containing xanthan were already densely packed in the die as a result of die filling leaving little void spaces. On the other hand, cissus formulations were not densely packed from die filling; as a result, it exhibited higher re-arrangement of its particles in the die during the initial stages of compression. This is in agreement with the report of Itiola and Pilpel (1986).

Table 2. Densities for the powder mixtures.

\begin{tabular}{ccccc}
\hline Formulation code & Loose bulk density $\left(\mathrm{g} / \mathbf{c m}^{3}\right)$ & Tapped density $\left(\mathbf{g} / \mathbf{c m}^{3}\right)$ & Relative density & Particle density $\left(\mathrm{g} / \mathbf{c m}^{3}\right)$ \\
\hline FC & $0.397 \pm 0.02$ & $0.529 \pm 0.02$ & 0.218 & $1.821 \pm 0.27$ \\
FC1 & $0.314 \pm 0.06$ & $0.402 \pm 0.05$ & 0.177 & $1.774 \pm 0.40$ \\
FC2 & $0.339 \pm 0.30$ & $0.441 \pm 0.01$ & 0.190 & $1.782 \pm 0.32$ \\
FC3 & $0.359 \pm 0.05$ & $0.495 \pm 0.05$ & 0.211 & $1.701 \pm 0.22$ \\
FX & $0.506 \pm 0.20$ & $0.626 \pm 0.02$ & 0.356 & $1.420 \pm 0.28$ \\
FX1 & $0.401 \pm 0.62$ & $0.544 \pm 0.05$ & 0.264 & $1.519 \pm 0.32$ \\
FX2 & $0.436 \pm 0.04$ & $0.566 \pm 0.10$ & 0.291 & $1.496 \pm 0.42$ \\
FX3 & $0.485 \pm 0.01$ & $0.617 \pm 0.06$ & 0.338 & $1.435 \pm 0.38$ \\
\hline
\end{tabular}

Table 3. Flow properties of Tramadol powder mixtures.

\begin{tabular}{cccc}
\hline Formulation code & Hausner's ratio & Carr's index (\%) & Angle of repose $\left(^{\circ}\right)$ \\
\hline FC & 1.333 & 24.95 & $52.75 \pm 0.20$ \\
FC1 & 1.281 & 21.89 & $43.36 \pm 0.09$ \\
FC2 & 1.302 & 23.13 & $47.51 \pm 0.27$ \\
FC3 & 1.378 & 27.50 & $56.27 \pm 0.36$ \\
FX & 1.238 & 19.17 & $32.61 \pm 0.62$ \\
FX1 & 1.357 & 26.29 & $41.39 \pm 0.14$ \\
FX2 & 1.299 & 22.97 & $38.37 \pm 0.25$ \\
FX3 & 1.273 & 21.39 & $34.08 \pm 0.52$ \\
\hline
\end{tabular}


The relative density, $D_{A}$, is the total degree of densification achieved which is equal to the tablet density produced.

The $P_{y}$ value gives an insight into the onset of plastic deformation during compression. It was observed from the values of $P$ obtained that as the concentration of polymer increases in all formulations containing the active ingredient, the $P_{y}$ decreased. Odeku et al. (2005) reported this trend in their study. The concentration of ingredients and interaction between these ingredients would determine the deformation characteristics and

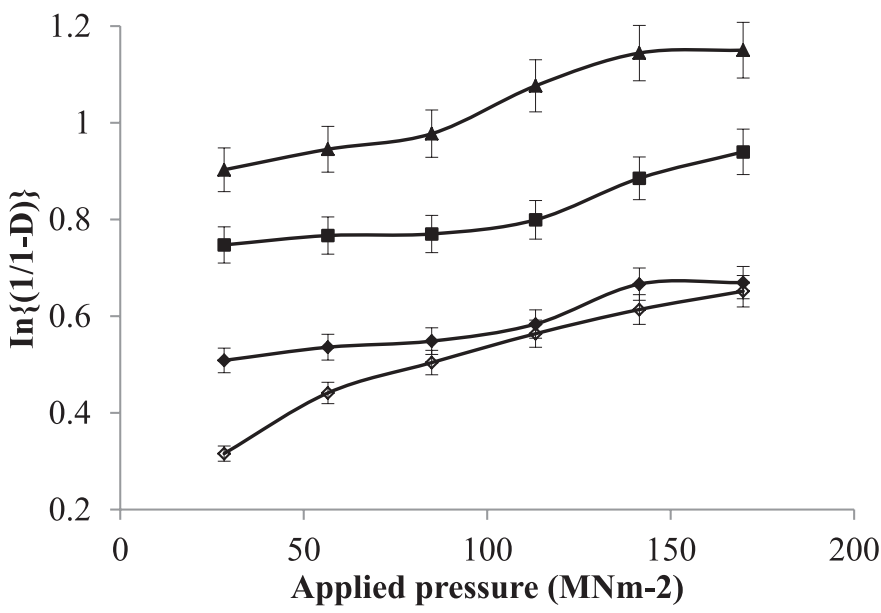

Figure 1. Heckel plots for formulations containing cissus gum matrices (FC- $\diamond$, FC1- $\bullet$, FC2-ø, and FC3-4).

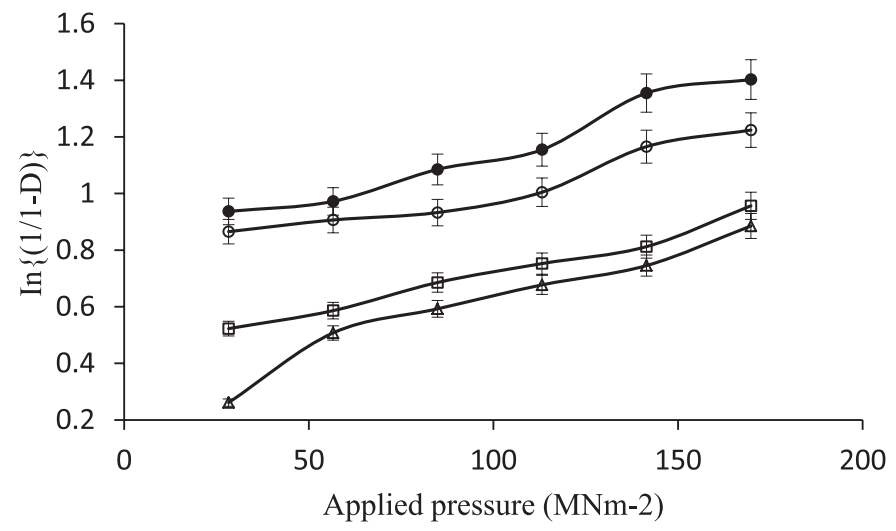

Figure 2. Heckel plots for formulations containing xanthan gum matrices (FX$\triangle$, FX1- $\square$, FX2-O, and FX3 •). plastic deformation would only begin once the yield value of any of the components is exceeded during compression. Xanthan gum formulations generally had a significantly lower $P_{y}$ value than cissus gum formulations ( $p=0.03$ ).

It was observed that the $P_{y}$ of the placebos, FC and FX, when compared with formulations FC3 and FX3 (all containing $75 \%$ of either xanthan gum or cissus gum and $25 \%$ of tramadol or lactose) had a faster onset of plastic deformation. The presence of the active ingredient, tramadol, prolonged the onset of plastic deformation. It was more extended in the formulations containing cissus gum (FC and FC3). This trend was observed with all other formulations. To overcome the retardation imposed, increase in the concentration of the polymer, compression pressure, and compression time is required. The type of medicament and nature of excipient are important factors in determining tablet quality; hence, selection and optimal polymer concentration are essential for optimal drug delivery.

\section{Mechanical properties of tablets}

The results of the crushing strength, tensile strength, and friability of the tablet formulations are presented in Table 5. Crushing and tensile strength are measures of tablet strength, while friability is a measure of its weakness. A general increase in crushing strength and decrease in friability was observed as the percentage of polymer increased in all formulations. This could be due to the plasto-elasticity nature of polymers in which increase in concentration during compression increases the degree of plastic deformation and subsequently leading to increase in the formation of more solid bonds in the tablet, thus leading to an increase in crushing strength. Also, as concentration of polymer increases in formulations, the number of particle-particle contact of the polymer increases, thereby increasing particle-particle interaction leading to the formation of a strong bond, which increases the mechanical strength of the tablet at high polymer concentrations. This agrees with the report of Adeleye et al. (2010); Adetunji et al. (2015); Patra et al. (2008); Thapa and Jeong (2018). However, formulations containing xanthan gum had a higher crushing strength, tensile strength, and lower friability, which were not significantly different when compared with formulations containing cissus gum $(p>0.05)$. This implies that xanthan gum has a slightly higher binding capacity (which is not statistically significant) than cissus gum. This could be supported by the results of particle density measurement of this study. It can be observed that xanthan gum having smaller particle density formed more cohesive compact.

Table 4. Parameters derived from density measurement and Heckel plots.

\begin{tabular}{ccccc}
\hline Formulation code & $\boldsymbol{P}_{\boldsymbol{y}}$ & $\boldsymbol{D}_{\boldsymbol{o}}$ & $\boldsymbol{D}_{\boldsymbol{A}}$ & $\boldsymbol{D}_{\boldsymbol{B}}$ \\
\hline FC & 434.78 & 0.218 & 0.251 & 0.116 \\
FC1 & 833.33 & 0.177 & 0.370 & 0.193 \\
FC2 & 714.29 & 0.190 & 0.495 & 0.305 \\
FC3 & 500.00 & 0.211 & 0.568 & 0.357 \\
FX & 250.00 & 0.356 & 0.221 & 0.012 \\
FX1 & 344.37 & 0.264 & 0.348 & 0.084 \\
FX2 & 370.37 & 0.291 & 0.529 & 0.238 \\
FX3 & 277.78 & 0.338 & 0.549 & 0.211 \\
\hline
\end{tabular}


Table 5. Mechanical properties of Tramadol tablet formulations prepared using cissus and xanthan gum matrices.

\begin{tabular}{cccc}
\hline Formulation code & Crushing strength $(\boldsymbol{N})$ & Tensile strength $\left(\boldsymbol{N} \mathbf{~ m m}^{-2}\right)$ & Friability $(\%)$ \\
\hline FC & $172.8 \pm 0.12$ & 2.524 & $0.63 \pm 0.07$ \\
FC1 & $74.8 \pm 0.06$ & 1.054 & $1.49 \pm 0.02$ \\
FC2 & $125.5 \pm 0.06$ & 1.802 & $0.98 \pm 0.03$ \\
FC3 & $153.6 \pm 0.02$ & 2.227 & $0.80 \pm 0.03$ \\
FX & $263.4 \pm 0.10$ & 3.932 & $0.26 \pm 0.03$ \\
FX1 & $128.7 \pm 0.02$ & 1.866 & $1.12 \pm 0.07$ \\
FX2 & $175.5 \pm 0.08$ & 2.563 & $0.70 \pm 0.11$ \\
FX3 & $246.6 \pm 0.04$ & 3.645 & $0.38 \pm 0.16$ \\
\hline
\end{tabular}

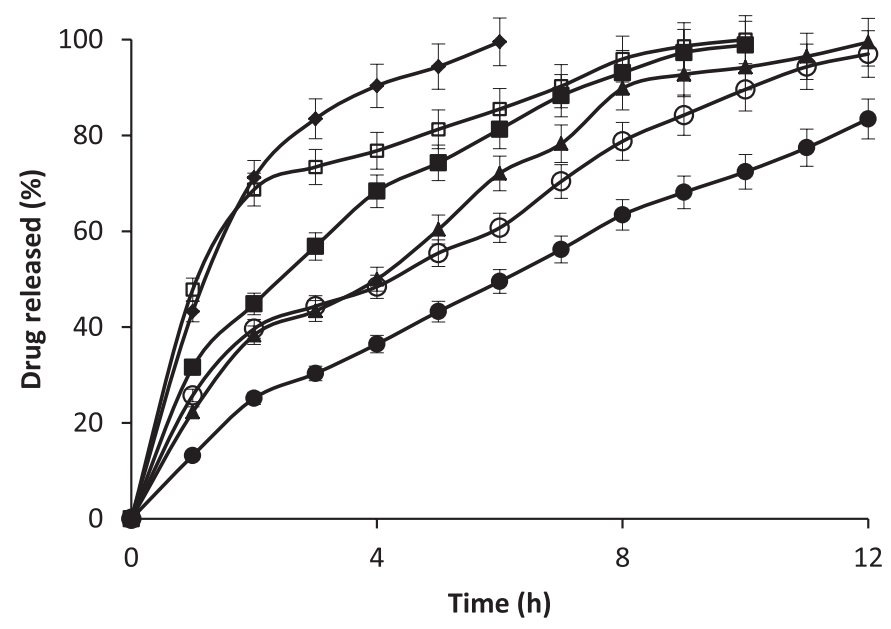

Figure 3. Release profiles of tramadol from cissus gum and xanthan gum

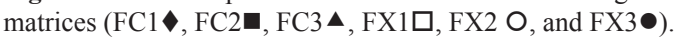

\section{Release properties of tablets}

The release profiles of tramadol from cissus and xanthan gum matrices are shown in Figure 3 as plots of percentage release of tramadol against time. As the concentration of the polymer in the formulations increased, the dissolution of tramadol tablets decreased. There was a significant difference in the dissolution of the matrix tablets with changes in the concentration of polymer $(p<$ 0.001). Xanthan gum extended drug release more than cissus gum.

\section{CONCLUSION}

Cissus gum had a good onset of plastic deformation forming a good cohesive compact which was slightly affected by the presence of tramadol hydrochloride. To compensate for this effect, the concentration of cissus gum, compression pressure, and compression time should be handled to produce tablets of good quality. This study concludes that cissus gum has some potentials and fundamental properties that would make it suitable as a direct compressible excipient in matrix systems for extended-release tablets after some adjustments in the formulation.

\section{REFERENCES}

Abioye AO, Odusote MO, Ifudu ND, Silva BO. A physicochemical basis for the stability effect of Cissus populnea gum in Oil-in-Water extemporaneous emulsions. J Pharm Sci Pharm Prac, 2000; $6: 17-22$.
Abioye AO, Odusote MO Ifudu ND, Silva BO. In vitro release kinetics of salicylic acid from Cissus populnea gel. J Pharm Sci Pharm Prac, 2001; 7:113-8.

Adeleye AO, Femi-Oyewo MN, Odeniyi MA. The effect of processing variables on the mechanical and release properties of tramadol matrix Tablets incorporating Cissus populnea gum as controlled release excipient. Polim Med, 2014; 44:209-20.

Adeleye AO, Femi-Oyewo MN, Odeniyi MA. Physicochemical and rheological characterization of Cissus populnea gum extracted by different solvents. West Afr J Pharm, 2015a; 26:113-26.

Adeleye AO, Femi-Oyewo MN, Odeniyi MA. Effect of compression pressure on mechanical and release properties of tramadol matrix tablets. Curr Issues Pharm Med Sci, 2015b; 28:120-5.

Adeleye AO, Odeniyi MA, Jaiyeoba KT. The influence of cissus gum on the mechanical and release properties of paracetamol tablets- a factorial analysis. J Basic Appl Pharm Sci, 2010; 31:131-42.

Adeleye AO, Odeniyi MA, Jaiyeoba KT. Evaluation of cissus gum as binder in a paracetamol tablet formulation. Farmacia, 2011; 59:85-96.

Adetunji OA, Odeniyi MA, Itiola OA. Effect of formulation and process variables on the release, mechanical and mucoadhesive properties of ibuprofen tablet formulations. Acta Poloniae Pharmaceutica Drug Res, 2015; 72:357-65.

Anroop B, Navpreet, MM, Ashok K, Lalit K. Studies on Ocimum gratissimum seed mucilage: evaluation of suspending properties. Indian $\mathrm{J}$ Pharm Sci, 2005; 67:206-9.

Bharadia PD, Patel GC, Patel MM. A preliminary investigation on sesbania gum as a pharmaceutical excipient. Int J Pharm Excipients, 2004; 1:102-5. $72: 163-8$

Carr R. Evaluating flow property of solids. Chem Eng, 1965;

Eichie FE, Amalime AE. Evaluation of the binder effects of the gum mucilages of Cissus populnea and Acassia Senegal on the mechanical properties of paracetamol tablets. Afr J Biotech, 2007; 6:2208-11.

Emeje M, Nwabunike P, Isimi C, Fortunak J, Mitchell JW, Byrn S, Kunle O, Ofoefule S. Isolation, characterization and formulation properties of a new plant gum obtained from Cissus refescence. Afr J Pharm Pharmacol, 2009; 3:16-23.

Fell JT, Newton JM. Determination of tablet strength by the diametral-compression test. J Pharm Sci, 1970; 59:688-91.

Gade R, Murthy T. Effect of hydrophilic and hydrophobic polymers on release kinetics of metoprolol succinate extended release tablets. Asian J Pharm, 2011; 5:101-6.

Genc L, Bilac H, Guler E. Studies on controlled release dimenhydrinate from matrix tablet formulations. Pharm Acta Helv, 1999; 74:43-9.

Giorgio P, Patrizia R. The safety of pharmaceutical excipients. Farmaco, 2003; 58:541-50.

Grond S, Sablotzki A. Clinical pharmacology of tramadol. Clin Pharmacokinet, 2004; 43:879-923. 
Hausner HH. Friction conditions in a mass of metal powders. Int J Powder Metall, 1967; 3:7-13.

Heckel RW. Density- pressure relationship in powder compaction. Trans Metal AIME, 1961; 222:671-5.

Hiestand EN, Well JE, Peot CB, Ocha JF. Physical processing of tableting. J Pharm Sci, 1977; 66:510-9.

Hindiyeh M, Altalafha T, Al-Naerat M, Saidan H, Al-Salaymeh A, Sbeinati L, Saidan MN. Process modification of pharmaceutical tablet manufacturing operations: an eco-efficiency approach. Processes, 2018; $6: 15$.

Ibrahim MA, Dawes VH, Bangudu AB. Evaluation of Cissus populnea polymer as a matrix former for controlled drug release. J Phytomed Ther, 2002; 5:23-32.

Itiola OA, Pilpel N. Tableting characteristics of metronidazole formulations. Int J Pharm, 1986; 31:99-105.

Itiola OA, Pilpel N. Formulation effects on the mechanical properties of metronidazole tablets. J Pharm Pharmacol, 1991; 43:145-7.

Jan SU, Khan GM, Hussain I. Formulation development and investigation of ibuprofen controlled release tablets with hydrophilic polymers and the effect of coexcipients on drug release patterns. Pak J Pharm Sci, 2012; 25:751-6.

Kaushik K, Sharma RB, Agarwal S. Natural polymers and their applications. Int J Pharm Sci Rev Res, 2016; 37:30-6.

Khan GM, Jiabi Z. Formulation and in-vitro evaluation of ibuprofen-carbopol 974 PNF controlled release matrix tablets III: Influence of co-excipients on release rate of the drug. J Control Rel, 1998; 54:185-90.

Kulkarni GT, Ambike SH, Ramsay MP. Evaluation of binding properties of Plantago ovata and Trigonella foenum graecum mucilage. Indian Drugs, 2002; 39:422-5.

Manjula BS, Srinatha A, Sridhar BK. Evaluation of hydrophilic polymers and their combinations in formulation of sustained-release matrix tablets of water-soluble drug. India J Pharma Edu Res, 2014; 48:48-59.

Marshall K. Compression and consolidation of powdered solids. In: Lachman L, Lieberman HA, Kanig JL (eds.). The theory and practice of industrial pharmacy. Varghese Publishing, Bombay, 1986.

Mohammadi MS, Harnby N. Bulk density modelling as a means of typifying the microstructure and flow characteristics of cohesive powders. Powder Tech, 1997; 92:1-8.

Muhammad TA, Shoaib H, Yousuf RI, Jabeen S, Muhammad IN, Tariq S. Use of hydrophilic and hydrophobic polymers for the development of controlled release tizanidine matrix tablets. Braz J Pharm Sci, 2014; 50:799-818.

Odeku OA, Awe OO, Popoola B, Odeniyi MA, Itiola OA. Compression and mechanical properties of tablet formulations containing corn, sweet potato and cocoyam starches as binders. Pharm Technol, 2005; 29:82-90.

Odeniyi MA, Onu RN, Adetunji OA. Evaluation of bioadhesive properties of natural and modified banana starches. East Central Afr J Pharm Sci, 2011; 14:34-42.

Patra CN, Pandit HK, Singh SP, Devi MV. Applicability and comparative evaluation of wet granulation and direct compression technology to Rauwolfia serpentine root powder: a technical note AAPS Pharm Sci Tech, 2008; 9:100-4.
Pawar H, D'mello PM. Isolation of seed gum from Cassia tora and preliminary studies of its application as a binder for tablets. Indian Drugs, 2004; 41:465-8.

Potu A, Veerareddy P, Jukanti R, Burra S. Formulation and evaluation of gum based matrix tablets of Lamivudine. Der Pharmacia Sinica, 2011; 2:176-92.

Prescot JK, Barnum RA. Powder flowability. Pharm Tech, 2000; $24: 60-84$

Raber M, Hoffman S, Junge K, Momberger H, Kuhn D. Analgesic efficacy and tolerability of tramadol $100 \mathrm{mg}$ sustained release capsules in patients with moderate to severe chronic low back pain. Clin Drug Invest, 1999; 17:415-23.

Reddy MS, Archana S. Formulation and evaluation of sustained release tablets of repaglinide using hydrophilic natural and synthetic polymers. Int J Pharm Sci Res, 2018; 9:2914-20.

Reus-Medina M, Lanz M, Kumar V, Leuenberger H. Comparative evaluation of the powder properties and compression behaviour of a new cellulose-based direct compression excipient and Avicel PH-102. J Pharm Pharmac, 2004; 56:951-6.

Singh PR, Shuaib M, Iqubal A, Singh M. Recent advances in direct compression technique for pharmaceutical tablet formulation. Int $J$ Pharma Res Dev, 2014; 6:49-57.

Staniforth J. Powder flow. In: Aulton M (ed.). Pharmaceutics, the science of dosage form design. Churchill Livingstone 197, Edinburgh, 2002.

Talukder M, Michoel MM, Rombaut AP, Kinget R. Comparative study on xanthan gum and hydroxypropylmethylcellulose as matrices for controlled release. Drug delivery 1. Int J Pharm, 1996; 129:231-41.

Thapa P, Jeong SH. Effects of formulation and process variables on gastroretentive floating tablets with a high-dose soluble drug and experimental design approach. Pharmaceutics, 2018; 10:16.

Varshosaz J, Tavakoli N, Eram SA. Use of natural gums and cellulose derivatives in production of sustained release metoprolol tablets. Drug Deliv, 2006; 13:113-9.

Williams RO, Reynolds TD, Cabelka TD, Sykora MA, Mahaguna $\mathrm{V}$. Investigation of excipient type and level on drug release from controlled release tablets containing HPMC. Pharm Dev Technol, 2004; 2:181-93.

\section{How to cite this article:}

Adeleye OA, Femi-Oyewo MN, Odeniyi MA, Ajala TO. Evaluation of Cissus populnea gum as a directly compressible matrix system for tramadol hydrochloride extended-release tablet. J Appl Pharm Sci, 2019; 9(02):105-111. 